\title{
A Retórica na Economia Institucional de Douglass North ${ }^{1}$
}

\author{
The rhetoric in Douglass North \\ Institutional Economics
}

PAULO GALA*

RESUMO: Este artigo analisa a retórica de Douglass North. Após uma breve discussão sobre a relevância dos estudos retóricos para fins metodológicos, investigamos o discurso do autor em Instituições, Mudança Institucional e Desempenho Econômico (1990) em duas etapas. A primeira lida com a maneira pela qual North fornece sua teoria - o foco principal aqui é na maneira como ele "fala" com seu público. A segunda mostra o uso do autor de algumas das regras retóricas clássicas propostas por Arida (1983). Na última seção, discutimos alguns aspectos do trabalho de North, considerando outros estudos com a mesma tarefa no Brasil.

PALAVRAS-CHAVE: Douglass North; nova teoria institucional.

ABSTRACT: This paper analyses the rhetoric of Douglass North. After a brief discussion about the relevance of rhetorical studies for methodological purposes, we investigate the author's speech in Institutions, Institutional Change and Economic Performance (1990) in two stages. The first deals with the way in which North delivers his theory - the main focus here is in the way he "talks" to his audience. The second shows the author's use of some of the classical rhetorical rules as proposed by Arida (1983). In the last section we discuss some aspects of North's work considering other studies with the same task in Brazil.

KEYWORDS: Douglass North; new institutional economics.

JEL Classification: B15; B31.

\footnotetext{
${ }^{1}$ Para o desenvolvimento deste texto o autor fica em débito com Luiz C. Bresser-Pereira, José Márcio Rego, Persio Arida, Ramon Fernandez, Arthur Barrionuevo, David Dequech e Gilberto Tadeu Lima, cabendo as isenções de praxe.

* Doutorando em economia pela Fundação Getúlio Vargas de São Paulo - FGV-SP, São Paulo/SP, Brasil. E-mail:pgala@uol.com.br
} 
We have much to learn from them [Veblen, Ayres e Marx], but not by abandoning neoclassical theory. Neoclassical theory has made economics the preeminent social science by providing it a disciplined, logical analytical framework. To abandon neoclassical theory is to abandon economics as a science. The challenge is to widen its horizons... ${ }^{2}$

O trabalho de Douglass North representa hoje uma referência essencial para a pesquisa voltada ao crescimento econômico e para o corpo do conhecimento de economia como um todo. A partir da publicação de Institutions, Institutional Change and Economic Performance, em 1990, e da obtenção do Prêmio Nobel de 1993, North passou a ser leitura obrigatória para todos que se interessam em estudar o desenvolvimento das economias no longo prazo e, mais especificamente, os determinantes da "riqueza e pobreza das nações". Seu approach, como sugere o título de sua principal obra sobre o tema, é institucionalista. O autor procura demonstrar como o crescimento de longo prazo ou a evolução histórica de uma sociedade é condicionado pela formação e evolução de suas instituições — "humanly devised constraints that shape human interaction" (North, 1990, p. 3).

Sua pesquisa não se inicia desde cedo na área institucional. Originalmente ligado ao grupo dos cliometristas, North desenvolve trabalhos de análise histórica, com grande inspiração em teoria econômica. Ao aplicar métodos quantitativos e insights da teoria econômica para o estudo da história, um grupo de economistas americanos fundou o que ficou conhecido na literatura como cliometria ou ainda a "nova história econômica" (ver Goldin, 1994, p. 2). Seus trabalhos principais são da década de 60 e 70 . Nesse grupo estavam, entre outros, economistas como Lance Davis, Robert Fogel, Anna Schwartz, Walt Rostow e Alexander Gerschenkron (McCloskey, 1998, p. 74 - para uma crítica da cliometria ver Hobsbawn, 1997, pp. 136-7). Dos trabalhos de Douglass North na época destaca-se a obra The Economic Growth of the United States 1790-1860 (North, 1966).

O marco da mudança de seu enfoque aparece na análise que Goldin (1994, p. 8) faz do texto Sources of Productivity Change in Ocean Shipping, 1600-1850, de 1968. Nesse estudo, North encontra um resultado curioso: o aumento da produtividade da indústria de transporte oceânico no período analisado decorreu muito mais de inovações e evoluções institucionais, entre as quais a redução da pirataria, do que das mudanças na tecnologia de transporte. Uma evolução institucional pareceu ser mais importante do que uma evolução tecnológica.

A partir de então, desenvolve uma série de trabalhos, principalmente de caráter histórico, que procuram entender o papel das instituições na evolução das sociedades, tanto primitivas quanto modernas. Encontramos aí várias obras de destaque. Institutional Change and American Economic Growth escrita em co-autoria com Lance Davis em 1971 faz uma leitura institucional da história norteamericana.

\footnotetext{
${ }^{2}$ North, 1978, p. 974.
} 
O clássico The Rise of the Western World, de 1973, escrita com Robert Paul Thomas, procura fazer uma leitura econômica não marxista da transição do feudalismo para o capitalismo. Em Structure and Change in Economic History, de 1981, o autor se propõe à arrojada tarefa de analisar toda a história econômica da humanidade, à luz de suas idéias sobre instituições. No texto de 1990 Institutions, Institutional Change and Economic Performance, analisa a dinâmica institucional das economias, encontrando, segundo nos conta, a resposta teórica de seu projeto.

Os esforços de Douglass North somados aos de alguns outros ensaístas Williamson, Coase, Demsetz, Alchian entre outros - deram origem ao programa de pesquisa que se convencionou chamar de Nova Economia Institucional (Rutherford, 1994, pp. 2-3). Essa agenda de trabalho vem apresentando vários frutos. Além do Nobel recebido por North, encontramos também a laureação de Ronald Coase em 1991. O volume da literatura novo institucionalista é crescente e, a se julgar pelo seu número de adeptos hoje, poderíamos dizer que essa corrente constitui, nos termos de Lakatos $(1979$, p. 161), um programa de pesquisa progressivo e não degenerativo.

Muito se discute atualmente sobre a natureza da obra de North - mais especificamente sobre o grau de neoclassicismo de seu pensamento. Sobre o posicionamento metodológico do autor encontramos classificações bastante extremadas, entre uma ortodoxia inequívoca e a heterodoxia. Nossa proposta neste artigo é acrescentar elementos à essa discussão metodológica por meio de uma análise da retórica de Douglass North. Partindo do pressuposto de que não se podem separar as etapas de construção e comunicação de uma teoria (McCloskey, 2000, p. 126), estudaremos com mais cuidado a natureza do discurso presente no livro de 1990. Procuraremos, assim, contribuir para um entendimento mais aprofundado da teoria proposta pelo autor. No que segue, o trabalho está dividido em quatro seções além desta introdução. Após uma brevíssima discussão acerca de análises retóricas em teoria econômica, estudamos a relação de North com sua audiência neoclássica, inspirando-nos no trabalho de D. McCloskey sobre Robert Fogel (McCloskey, 1998). Seguimos mostrando em North algumas das clássicas formas retóricas encontradas na história do pensamento econômico como propõe Arida (1983). A última seção conclui o texto.

\section{RETÓRICA EM ECONOMIA}

A tradição de análises retóricas é relativamente recente em economia. Nos Estados Unidos, tendo seu principal representante em D. McCloskey - a partir de seu paper seminal de 1983, The Rhetoric of Economics, no Journal of Economic Literature - e no Brasil, a partir da publicação do texto A História do Pensamento Econômico como Teoria e Retórica, de Persio Arida, também em 1983. Evidentemente, a questão da utilização da retórica em economia não se resume a esse período. Desde seu papel na obra de Adam Smith, professor de retórica, passando por sua importância nos trabalhos de Coase, Muth, Paul Samuelson — analisados 
por McCloskey - Keynes e muitos outros, parece bastante difícil entender a evolução da história do pensamento econômico sem o reconhecimento de diversos movimentos retóricos (Arida, 1996, p. 35). Daí não decorre, entretanto, que a utilização desta chamada arte seja benéfica ou salutar para o progresso de nossa ciência - como bem mostra a controvérsia a seguir.

Para os assim chamados partidários da retórica, perguntar se o uso desta é nocivo ao conhecimento humano constitui-se num falso problema. Qualquer forma de comunicação tem implícita uma retórica — boa ou ruim. Como bem aponta McCloskey, uma utilização preconceituosa desse termo esteriliza sua maior contribuição, a saber, a busca da "grande razão" por meio da conversa e do debate: "Não minta, preste atenção, não burle; coopere; não grite; deixe que falem os demais; seja imparcial; explique-se quando perguntarem; não recorra à violência ou à conspiração em ajuda de suas idéias..." são regras que fazem parte da Sprachethik, como diz McCloskey inspirando-se no filósofo alemão Jurgen Habermas (McCloskey, 1996, p. 66). Para seus críticos, o recurso excessivo a técnicas de persuasão desvirtua a atividade científica na medida em que se perde de vista a busca da verdade em detrimento do convencimento.

Segundo uma abordagem "otimista", a conversa, a discussão, o debate, enfim, a boa retórica, constitui-se num possível caminho de avanço do conhecimento. Boa conversa significa boa ciência (McCloskey, 1996, p. 69). A retórica é, portanto, entendida, do ponto de vista de Aristóteles, como algo construtivo (Rego, 1996, pp. 135-6 e McCloskey, 1996, pp. 71-2), jogando papel importante na busca da verdade. Contribui para o aumento da "razoabilidade" científica por meio da discussão, opondo-se claramente à "idéia de que retórica é o oposto da lógica” (Fernández, 2000, p. 3), significando, portanto, "pensamento explorado pela conversação" nos termos de McCloskey — de outra maneira, uma retórica filosófica (Anuatti Neto, 1994, p. 13).

$\mathrm{Na}$ visão pessimista, a retórica busca convencer e persuadir, e não a verdade. Nesse sentido, boas teorias serão aquelas convincentes e, portanto, capazes de converter a maioria dos cientistas, "pois a função das teorias e hipóteses científicas não é a busca da quinta roda inoperante [a verdade]; a causa de sua existência é serem persuasivas, interessantes, razoáveis, terem apelo. Assim, boa teoria é a teoria que convence mais, que persuade a platéia e os interlocutores. Tornando-nos todos vítimas, assim, dos magos da retórica, por piores que possam ser suas intenções” (Paulani, 1996, p. 109).

Como argumentam Aldrighi e Salviano (1996), muitas das técnicas retóricas podem, por vezes, ser completamente nocivas à boa ética científica, “....a mera consulta a um manual de retórica permite concluir que há muitas figuras retóricas cujo uso conflita com os ideais de clareza e honestidade que McCloskey subscreve" (Aldrighi e Salviano, 1996, p. 90). A retórica é vista com destaque para sua conotação negativa, "um engano verbal, como na 'retórica vazia', ou em 'mera retórica'" (McCloskey, 1996, p. 70). Privilegia-se assim seu aspecto agonístico, em que seus praticantes visariam a "participar de um campeonato na arte de persuadir" (Paulani, 1996, p. 109) — como também mostra Rego (1996) ao analisar a origem 
dessa discussão com Górgias, Sócrates e Platão. Na caracterização apresentada por Anuatti Neto (1994, p. 12), uma retórica sofista.

A controvérsia não é facilmente solucionável. Como bem apontam Bianchi e Salviano (1996), no limite, parece bastante difícil conciliar as posições de discurso persuasivo de um lado e conversa civilizada de outro. "Querer convencer e querer dizer a verdade não são incompatíveis, mas também não são substitutos" (Bianchi e Salviano, 1996, p. 175). Menos controversa é a questão da utilidade de estudos retóricos para a compreensão do avanço da ciência econômica. Se admitirmos que toda teoria tem um momento retórico, já que deve ser necessariamente comunicada a um grupo de cientistas, análises com vistas a esse aspecto podem enriquecer $\mathrm{o}$ entendimento da dinâmica de idéias na história do pensamento econômico. Ao se analisar o discurso dos empreendedores ou arquitetos desse campo de conhecimento, tem-se uma visão muito mais clara e rica de sua formação. É com esta inspiração metodológica que seguimos abaixo estudando a construção da teoria de North.

\section{DOUGLASS NORTH COMO RETÓRICO}

Como nos mostram Perelman e Tyteca (2000, p. 24) um dos principais prérequisitos para esforços de convencimento passa pela identificação e interação com o conjunto de crenças preexistentes na mente de um receptor; a relação debatedorplatéia. Para que a comunicação seja bem-sucedida, deve haver um terreno comum, partilhado pelas partes envolvidas no processo. Uma retórica bem praticada consiste em identificar tais crenças ou paixões preexistentes para depois moldar a idéia a ser transmitida no sentido de sintonizá-la à mente, ou filtro cognitivo do receptor (ver Dib, 2001, p. 16). Vejamos como North nos tenta convencer da possibilidade de integração do instrumental institucionalista à teoria neoclássica e de como estudar instituições representa algo relevante para teoria econômica.

Inicialmente, faz questão de apresentar seu "aparato" como complementar à economia neoclássica. Apresenta, em seguida, a possível omissão desta em relação à incorporação de algum instrumental do tipo institucionalista de forma branda, como uma "não-apreciação" (North, 1990, p. 3). Segue insistindo na tentativa de integrar a teoria vigente às suas idéias. Diferentemente de Keynes, que ampliou suas diferenças com Marshall como estratégia persuasiva (Anuatti Neto, 1994, p. 194), observamos que North prefere adotar "uma estratégia retórica de minimizar divergências e maximizar semelhanças", como tipifica Anuatti Neto (1994, p. 179). Nas duas primeiras páginas do livro utiliza as palavras "complementaridade", "reconciliação" na sequência e "integração" por duas vezes, afirmando, claramente, perto do final da primeira seção, "defining institutions as the constraints that human beings impose on themselves makes the definition complementary to the choice theoretic approach of neoclassical economic theory" (North, 1990, p. 5). Apesar de definir objetivamente o que entende ser os postulados da teoria neoclássica (North, 1990, p. 19), parece transformá-la, ao longo da obra, num ente com funcionalidade retórica. Ao dialogar no texto com esse "ser", facilita a compreensão 
de sua platéia. Ao tentar "se conciliar" com os "neoclássicos", faz-nos lembrar de Keynes, que "inventou" os clássicos para polemizar (Arida, 1996, p. 40). Há sempre a preocupação em North de obter uma identificação com seu público ou audiência.

Já no primeiro capítulo, apresenta suas idéias referindo-se explicitamente à teoria neoclássica (North, 1990, p. 3). É fato que o autor também se diz preocupado com a leitura do público não economista, principalmente de cientistas sociais (North, 1990, p. viii). Também, por momentos, North "conversa" com a teoria marxista e com historiadores em geral. Mas o núcleo de sua obra direciona-se primordialmente para a "current economic theory" e "cliometric history", em seus próprios termos. Boa prova dessa postura encontra-se na análise do capítulo 2 . O autor utiliza seis páginas para analisar e resenhar o que havia de mais recente em teoria dos jogos - por que não resenhar a teoria marxista? - para depois concluir que nenhuma destas empreitadas havia trazido grandes avanços. Ora, se essas teorias não apresentaram resultados tão promissores, por que então apresentá-las, senão como uma maneira de convencer o leitor neoclássico a respeito disso? A partir de uma leitura mais atenta, podemos identificar o cuidado do autor em conversar com um "suposto leitor" a respeito da teoria que é apresentada. Sempre levando em consideração prós e contras e analisando outras alternativas, North procura mostrar a relevância de sua proposta.

Apesar de um movimento insistente de conciliação, percebemos, ao longo do livro, que a complementaridade entre a teoria de North e a escola neoclássica é, no mínimo, controversa (ver, por exemplo, North, 1990, p. 135). Podemos citar dois dos principais pilares do pensamento de North que podem ir contra a teoria neoclássica - tomando por base a definição de Mario Possas (1997, p. 15 e p. 34):

i) A defesa de uma teoria de racionalidade "processual" como desenvolvida porHerbert Simon, que também possa incluir de alguma forma cooperação e altruísmo. A não-aceitação da racionalidade substantiva ou "rational choice".

ii) A utilização de uma teoria de múltiplos equilíbrios e retornos crescentes, fortemente baseada no conceito de "path dependence" como desenvolvida por Brian Arthur e Paul David.

North prefere começar o trabalho sem dar destaque a essas divergências, que só serão encontradas ao longo do texto (ver North, 1990, p. 131). Ao levantar alguns temas teóricos controversos, como, por exemplo, o problema da convergência entre países pobres e ricos, North se limita a dar parcos contra-argumentos de abrangência, ressaltando, porém, as virtudes desse modelo. Inicia uma crítica, mas interrompe-a rapidamente para dar o que se poderia chamar de uma "reviravolta retórica". Em vez de atacar seu público, os neoclássicos, opta por fazer uma discussão de toda a sua trajetória intelectual ao longo de seus últimos 17 anos. A clássica construção do ethos ou a apresentação do autor de tal modo que inspire confiança e credibilidade ao leitor. Como aponta McCloskey (1998, p. 7) e os ma- 
nuais de retórica gregos, não há como persuadir sem que o público confie no orador ou escritor (ver Crowley, 1999, p. 112).

Para finalizar o primeiro capítulo, North conclui com uma breve discussão histórica sobre a evolução dos Estados Unidos, contrastada à situação dos países de Terceiro Mundo hoje. Nesse ponto, aparece o apelo à erudição. O autor mostra, rapidamente, que conhece bastante sobre história econômica. Mais do que isso, tenta já associar sua teoria a "dados empíricos" conferindo à mesma um caráter de cientificidade, além da abrangência garantida por análises históricas. Ao longo do livro encontramos várias passagens que procuram dar um "tom científico" ao trabalho, outra estratégia de convencimento destacada por McCloskey (ver, por exemplo, North, 1990, p. vii).

Ainda sobre a questão de estilo, cabe ressaltar uma estratégia de argumentação típica de persuasão: a paramologia ou "admittance" (Lanham, 1991, p. 2, 194). Como aponta McCloskey (1998, p. 164) em seu estudo sobre Fogel, movimentos desse tipo constituem-se em conceder aspectos secundários inicialmente, seja por conviç̧ão seja para dar força ao argumento oposto, para ganhar outros mais importantes na seqüência. Esse tipo de expediente é utilizado de forma recorrente ao longo do livro. Passagens como "Although we do observe some convergence among leading industrial nations that trade with each other, an overwhelming feature of the last ten millennia is that we have evolved into radically different religious, ethnic, cultural, political, end economic societies (North, 1990, p. 6)" se repetem muitas vezes. Ao criticar o modelo neoclássico de forma mais incisiva, utiliza-se várias vezes dessa forma de argumentação. Num dado momento do texto define o que seria o melhor sumário das hipóteses comportamentais do modelo neoclássico (North, 1990, p. 19). Segue desmontando as bases desses pressupostos nas páginas seguintes para depois concluir o capítulo com uma série de admittances (ver North, 1990, p. 24).

Poderíamos seguir aqui analisando mais traços do estilo de North. Não temos nem o espaço nem o interesse para tal. Importa-nos reter a preocupação do autor com a apresentação de seu texto. Cada movimento argumentativo tem o objetivo de preparar o terreno para a introdução das idéias. A preocupação em dialogar com sua audiência neoclássica é nítida. Percebemos tal atitude a partir do cuidado em identificar e interagir com as idéias e crenças supostamente presentes na cabeça de seu leitor implícito.

\section{A CONTRIBUIÇÃO DE NORTH COMO TEORIA E RETÓRICA}

A principal proposta de Arida (1983) está em explicar a sucessão de modos de pensamento na história das idéias econômicas. Influenciado por idéias de Kuhn, Lakatos e Granger, entre outros, procura formular uma teoria capaz de explicar a dinâmica de idéias em economia a partir do "colapso da epistemologia falsificacionista" (Arida, 1996, p. 35). No modelo retórico hermenêutico, uma teoria capaz de reinterpretar suas rivais em seus próprios termos e convencer novos e muitos adeptos 
da utilidade epistemológica de seu tipo de abordagem terá grande chance de sucesso. A proximidade de Lakatos aqui é significante. As teorias que forem capazes de explicar fenômenos já tratados por outras escolas e acrescentarem luz ao entendimento de novas observações serão as vitoriosas. A tenacidade de Lakatos transforma-se em subsunção ardilosa para Arida. O embate entre as teorias se dá no plano argumentativo, onde "o empírico" entra tão-somente como um entre outros critérios de desempate. Nessa disputa, as regras e estratégias retóricas adquirem grande relevância. Vejamos Douglass North em seu texto de 1990, seguindo Arida.

De partida, podemos mencionar a sábia regra da utilização de metáforas. A utilização destas na ciência econômica tem longa história (lembremos da clássica metáfora da "mão invisível" de Adam Smith). Segundo Arida, o mais importante, entretanto, é a sábia utilização delas - já que por definição todo modelo é de alguma forma metafórico (Arida, 1996, p. 42). Não por acaso, North apresenta sua metáfora principal — instituições como regras de um jogo — já na segunda página de seu primeiro capítulo (North, 1990, p. 4). Num segundo exemplo, encontramos a regra da abrangência. Como aponta Arida, modelos ou idéias capazes de explicar ou dar conta de mais fenômenos têm uma tendência maior à aceitação. Sendo um historiador econômico, North irá se utilizar recorrentemente do expediente de "trazer a história" como subsídio às suas idéias.

Uma das peças fundamentais do modelo proposto por Arida está no movimento de subsunção entre teorias: a regra da generalidade ou a tentativa de subsumir as teorias alheias à nova teoria proposta. Exemplos nesse sentido são fartos. Marx tentou subsumir os mercantilistas, os fisiocratas e a economia política clássica em sua teoria do capital a partir dos conceitos de capital dinheiro, capital mercadoria e capital produtivo (Arida, 1996, p. 40). Jevons advogava que sua teoria do valor era "mais geral" e, portanto, podia explicar a tese do valor trabalho como um caso específico de sua teoria (Jevons, 1983, p. 105). Bastante conhecida também é a estratégia de Keynes ao dizer que o modelo clássico era válido somente para um caso específico - ou estado - de uma economia de mercado, a saber, o ponto de pleno emprego (Keynes, 1964, p. 3).

Ao longo do livro de 1990, encontramos várias passagens onde North reduz a teoria neoclássica a um caso especial do institucionalismo que propõe; a um conjunto de instituições específicas. Tenta mostrar que seus "adversários" não são capazes de explicar muito do que observamos na história, pois seus modelos se aplicam somente a "casos e momentos específicos do tempo". "In a world in which there are no increasing returns to institutions and markets are competitive, institutions do not matter" (North, 1990, p. 95). "[...] Institutions, together with the standard constraints of economic theory, determine the opportunities in a society" (North, 1990, p. 7). "[...] what behaviour then is consistent with an institutionsfree world?” (North, 1990, p. 18). “[...] Incentives are the underlying determinants of economic performance. They are implicit in the theories we have employed and assumed to have a particular form and effect" (North 1990, p. 135) [grifos nossos].

A questão de formas gerais e particulares em teorias apresenta-se com alguma controvérsia. Em geral, veremos autores propondo, como faz North, que seus mo- 
delos são mais gerais e, portanto, mais significantes. Pode-se-ia se argumentar que existem critérios objetivos para qualificar teorias como gerais ou particulares; por exemplo, quando um argumento é capaz de substituir constantes por variáveis, para usar os termos de Arida (1996). Infelizmente, a relação entre teorias não pode ser entendida sob prisma tão simplificador (Arida, 1996, p. 39). Uma discussão aprofundada a esse respeito está fora do escopo deste trabalho. Cabe, entretanto, citar mais um exemplo com o intuito de ilustrar a importância retórica dessa regra.

Partindo da própria referência à estratégia de Keynes que tenta subsumir os clássicos, vemos, a partir de Arida (1996, p. 41), que na síntese neoclássica os adversários de Keynes voltam a subsumi-lo e, na seqüência desse embate, os póskeynesianos tentam novamente subsumir os neoclássicos. Dentro da própria disputa entre seguidores de Keynes surge discussão parecida. Numa das controvérsias entre pós e novos Keynesianos encontramos um genuíno confronto de generalidade. Davidson (1995) procura mostrar que seu conceito de não-ergodicidade requer menos axiomas para obter resultados keynesianos e, portanto, representa uma teoria mais geral. Rosser (1996), por sua vez, ao utilizar o ferramental de chaos e sunspots defende que sua teoria requer menos do que as condições de linearidade implícitas na proposta de Davidson e que, portanto, é matematicamente mais geral (Rosser, 1996, p. 12).

Disputas de generalidade persistem na ciência econômica. A estratégia de North ao tentar absorver a teoria neoclássica como um caso particular da sua carrega enorme poder de persuasão. Entretanto, argumenta Arida, somente o esforço de generalização não é suficiente. Há que se fazer um movimento no sentido de reinterpretação de idéias antigas em novos termos. Daí a importância do aspecto hermenêutico do modelo que propõe. A teoria "vencedora" deverá ser capaz de reinterpretar a "derrotada" em seus próprios termos. Aqui, novamente, encontramos pistas da estratégia de North. Como aponta Arida, o surgimento da escola cliométrica na década de 60 pode ser entendido como a vitória final do paradigma neoclássico sobre seus adversários do final do século XIX. Nessa esteira, a reinterpretação ou reciclagem por North de idéias presentes nos velhos institucionalistas americanos - Veblen, Comons e Ayres -, influenciados em sua origem pela escola histórica alemã, constitui também importante movimento para a consolidação de suas idéias e avanço do paradigma neoclássico.

\section{CONSIDERAÇÕES FINAIS}

Para finalizar, utilizamo-nos agora de alguns autores que perceberam o movimento retórico da obra de North sem, contudo, nomeá-lo. Sebastião C. Velasco e Cruz por exemplo, ao discutir o trabalho de North, toca, sem perceber, no pontochave de nosso texto: "devemos levar em conta essa relação tensa, mas umbilical, com a economia neoclássica para entender a maneira como ele [o texto de North] será abordado. Sim, porque embora a critique e dela se afaste em vários pontos e de muitas maneiras, a economia neoclássica continua constitutivamente presente na obra 
tardia de North - como quadro de referência no contexto do qual formula seus problemas e 'língua materna' à qual retorna constantemente em busca dos instrumentos conceituais de que necessita para pensá-los” (Velasco e Cruz, 2001, p. 4).

A funcionalidade do linguajar neoclássico parece causar problemas em leituras que procuram precisar a posição metodológica de Douglass North. Toyoshima (1999), por exemplo, defende a postura neoclássica de North a partir, apenas, de auto-intitulações do autor. Velasco e Cruz identifica de forma mais clara um "estranho" hibridismo no comportamento de North; "podemos confirmá-lo ao observar o uso canhestro de categorias da análise neoclássica a esferas de problemas e a campos semânticos que originalmente lhes eram estranhos, e que só as comportam como metáforas vagas e ineptas, como nas passagens que se seguem...” (Velasco e Cruz, 2001, p. 4). Bernardo G. Macedo (2001) também toca na estratégia de Douglass North ao abordar a maneira com a qual o autor usa o conceito de path dependence: "a idéia de path dependence é facilmente 'cooptável' por modelos que, de resto, se baseiam em pressupostos neoclássicos, mesmo que muitas vezes com seu reducionismo mitigado, ou pode ser aplicada estritamente a modelagens não-neoclássicas de sistemas ou trajetórias" (Macedo, 2001, p. 363).

Ao utilizar "sabiamente" a linguagem econômica neoclássica, North é capaz de conversar de forma bastante "eficaz" com seus pares. Afinal, sem o convencimento e o consentimento dos mesmos, não haveria como sua teoria "vingar". Após criticar a utilização "canhestra" (sic) de termos feita por Douglass North, Velasco e Cruz identifica, sem aprovação - assim como faz Antonio Maria da Silveira em sua análise sobre o trabalho de Buchanan (Silveira, 1996) - , a estratégia de sucesso do autor: "a economia institucional de North nada tem de iconoclasta. Ele não quer demolir, nem sequer abandonar um terreno batido para explorar novas paragens, armado de outras metáforas. Sua tarefa é a de um reformador moderado. O procedimento que adota para esse fim é bastante simples. Identificando dificuldades da teoria neoclássica no trato de certos problemas - ou questões por ela silenciadas - passa a reexaminar os seus supostos, a fim de introduzir-lhes as alterações necessárias para acomodar os fenômenos problemáticos. A expectativa é de que por essa via a tradição, que é a sua, venha a ser enriquecida. A idéia de romper com ela não parece tentá-lo" (Velasco e Cruz, 2001, p. 5).

$\mathrm{Na}$ formulação de Aguiar de Medeiros, "esta construção metodológica em que o ato econômico inicia-se com a troca por meio da ação individual, num mercado abstrato, para num momento seguinte acrescentar as empresas e instituições como dispositivos funcionais, é típica do dedutivismo e do reducionismo que perpassa a análise de North. Faz parte de seu programa de pesquisa estender o individualismo metodológico à análise institucional” (Medeiros, 2001, p. 78). Como nos informa North na epígrafe que abre o artigo, "abandonar a economia neoclássica significaria para ele abandonar a própria ciência econômica...”. Cabe portanto, por fim, definir mais precisamente a posição metodológica de Douglass North. Ao se utilizar com grande eficácia da arte retórica — tomada em seus sentidos sofista e filosófico — o autor logra êxito em ampliar as fronteiras do ferramental neoclássico. Numa prática que poderia ser caracterizada por ciência normal (em termos kuhnianos) 
ou ampliação do cinturão protetor (em termos lakatosianos), North constrói uma obra de ortodoxia ampliada. Traz em seu bojo, naturalmente, alguns pontos heterodoxos necessários à ampliação de tal arcabouço teórico.

\section{REFERÊNCIAS BIBLIOGRÁFICAS}

ABRAMOVAY, R. "Desenvolvimento e instituições: a importância da explicação histórica”, em Razões e ficções do desenvolvimento, Arbix, Zilbovicius e Abramovay (orgs.), Editora Unesp; Edusp, São Paulo, 2001.

ALDRIGHI, D. e SALVIANO, C. “A Grande Arte: A Retórica para McCloskey”, em Retórica na Economia, José Márcio Rego (org.), Editora 34, São Paulo, 1996.

ANUATTI NETO, F. Persuasão Racional em Keynes: uma aplicação de retórica em história das idéias econômicas, Tese de Doutorado, FEA-USP, São Paulo, 1994.

ARIDA, P. “A História do Pensamento Econômico como Teoria e Retórica” em Retórica na Economia, José Márcio Rego (org.), Editora 34, São Paulo, 1996 - segunda versão do trabalho publicado originalmente em 1983 como texto para discussão PUC/RJ.

BIANCHI, A. e SALVIANO, C. "Prebisch, a Cepal e seu discurso", em Retórica na Economia, José Márcio Rego (org.), Editora 34, São Paulo, 1996.

BLAUG, M., The Methodology of Economics or how economists explain, Cambridge University Press, Cambridge, 1997.

BRESSER-PEREIRA, L. C. “Método e Paixão em Celso Furtado”, em A Grande Esperança em Celso Furtado, José Márcio Rego e Luiz Carlos Bresser-Pereira (orgs.), Editora 34, São Paulo, 2001.

“Entrevista”, em Conversas com Economistas Brasileiros, José M. Rego, L.F. Cozac e C. Biderman (orgs.), Editora 34, São Paulo, 1996.

e LIMA, G. T. “The irreductibility of macro to microeconomics: a methodological approach”, Revista de Economia Política, Volume 16, n.2(62), Abr/Jun 1996.

CAPORASO, J.A., e LEVINE, D.P. Theories of Political Economy, Cambridge University Press, Cambridge, 1992.

CROWLEY, S. e HAWHEE, D. Ancient Rhetorics for Contemporary Students, Allyn \& Bacon, Boston, 1999.

DAVIDSON P. "Reality and Economic Theory”, University of Tennessee, Discussion Paper, 1995.

DENZAU, A. T. e NORTH, D. "Shared Mental Models: Ideologies and Institutions”, Kyklos, Vol.47, 1994.

DEQUECH, D. “Bounded Rationality, Institutions and Uncertainity”, texto a ser publicado no Journal of Economic Issues, Dez, 2001 (a)

"Incerteza num sentido forte: significado e fontes", em Macroeconomia Moderna, Lima, Sicsú e de Paula (orgs.), Editora Campos, São Paulo, 1999.

"The new institutional economics and the theory of behaviour under uncertainty", texto do II Seminário Brasileiro da NEI, 2001 (b)

DIB, D. A controvérsia do Planejamento na Economia Brasileira: a retórica como instrumento de formação de crenças, USP, Dissertação de Mestrado, São Paulo, 2001.

EGGERTSSON T. "A note on the economics of institutions” em Empirical Studies in Institutional Change, Alston L., Eggertsson T., North D., (eds), Cambridge University Press, Cambridge, 1998 (1 $1^{\mathrm{a}}$ ed. 1996).

FERNÁNDEZ, R. “A retórica e a procura da Verdade em Economia” em Retórica na Economia, José Márcio Rego (org.), Editora 34, São Paulo, 1996.

e PESSALI, H.F. "Oliver Williamson and the rhetorical construction of the Transaction Cost Economics", Trabalho discutido em encontro da Sociedade de Economia Política, 2000.

“Teoria dos custos de Transação e Abordagens Evolucionistas: Análise e Perspectivas de um Programa de Pesquisa Pluralista”, Revista de Economia Política, Volume 21, nº 2 (82), Jun 2001. 
GALA, P. e REGO, J.M. “A Retórica em Douglass North”, texto apresentado no IV Encontro de Economistas de Língua Portuguesa, Portugal, 2001.

GARCIA, F., GOLDBAUM, S., VASCONCELOS, L., REBELO, A. “Instituições e Crescimento: a Hipótese do Capital-efetivo", texto para discussão FGV-SP no 81, São Paulo, 1999.

GOLDBAUM, S. O postulado da racionalidade e a nova economia institucional: a nova teoria da firma, Dissertação de Mestrado FGV-SP, São Paulo, 1996.

GOLDIN, C. "Cliometrics and the Nobel", National Bureau of Economic Research, Historical Paper $\mathrm{n}^{\circ}$ $65,1994$.

HOBSBAWN, E. "Historiadores e Economistas: II”, em Eric Hobsbawn sobre História, Companhia das Letras, São Paulo, 1997.

JEVONS, W. S. “A teoria da Economia Política”, em Os Economistas, Jevons, Editora Abril, São Paulo, 1983.

KEYNES, J.M. “The General Theory and After: Preparation”, The Collected Writings of John Maynard Keynes, ed. por D. Moggridge, vol. XIII, McMillan, London, 1973.

The General Theory of Employment, Interest, and Money, Harcourt Brace, New York, 1964.

A Teoria Geral do Juro do Emprego e da Moeda, Atlas, São Paulo, 1992.

LANHAM, R.A. A Handlist of Rhetorical Terms, University of California Press, Los Angeles, 1991.

LAKATOS, I. “O Falseamento e a Metodologia dos Programas de Pesquisa Científica”, em A Crítica e o Desenvolvimento do Conhecimento, Lakatos e Musgrave (orgs.), Cultrix-Usp, São Paulo, 1979.

MACEDO, B. G. "A concepção de história em Douglass North e na Economia do Desenvolvimento", texto do II Seminário Brasileiro da Nova Economia Institucional, Campinas, 2001.

MCCLOSKEY, D. The Rhetoric of Economics, University of Wisconsin Press, Wisconsin,1998 (2 $2^{\mathrm{a}} \mathrm{ed}$.).

“A Retórica da Economia”, em Retórica na Economia, José Márcio Rego (org.), Editora 34, São Paulo, 1996.

"The Rhetoric of Economics", Journal of Economic Literature, 21, 1983.

Knowledge and Persuasion in Economics, Cambridge University Press, Cambridge, $2000\left(1^{\mathrm{a}}\right.$ ed. 1994).

Economical Writing, Waveland Press, Estados Unidos, 2000 (2 ${ }^{\mathrm{a}}$ ed.).

MEDEIROS, C. A. "Rivalidade estatal, instituições e desenvolvimento econômico" em Polarização

Mundial e Crescimento, José Luís Fiori e Carlos Medeiros (orgs.), Editora Vozes, Petrópolis, 2001

MORAES JUNIOR, A.C. "O Conceito de Eficiência na Nova Economia Institucional”, trabalho apresentado em Congresso, ANPEC, 2000.

NORTH, D. Structure and Change in Economic History, Norton, New York, 1981.

Institutions, Institutional Change and Economic performance, Cambridge University Press, Cambridge, 1990.

e Robert P. Thomas. The Rise of the Western World: A New Economic History, Cambridge University Press, Cambridge, 1973.

"Structure and Performance: The Task of Economic History", Journal of Economic Literature, 16, 1978.

e DAVIS, L. Institutional Change and American Economic Growth, Cambridge University

Press, Cambridge, 1971.

"Autobiography", The Bank of Sweden Prize in Economic Sciences in Memory of Alfred

Nobel, 1993.

"Understanding the process of Economic Change", Iea Occasional Paper, London, 1999.

"Epilogue: economic performance through time", em Empirical Studies in Institutional

Change, Alston L., Eggertsson T., North D., (eds), Cambridge University Press, Cambridge, 1998

(1 $1^{\mathrm{a}}$ ed. 1996).

The Economic Growth of the United States 1790-1860, WW Norton \& Company, New

York, 1966 (Originalmente publicada em 1961, Prentice Hall).

"Institutions, transaction costs, and the rise of merchant empires", em The Political Eco- 
nomy of Merchant Empires, State Power and World Trade 1350-1750, James D. Tracy (ed.), Cambridge University Press, Cambridge, 1997, (1ed. 1991).

PAULANI, L.M. "Idéias sem lugar - Sobre a retórica na economia de McCloskey" em Retórica na Economia, José Márcio Rego (org.), Editora 34, São Paulo, 1996.

"Modernidade e discurso econômico - ainda sobre McCloskey", Revista de Economia Política, Volume 19, nº 4(76), Dez 1999.

PERELMAN, CH. e TYTECA, L., O. The New Rhetoric, a Treatise on Argumentation, University of Notre Dame Press, Notre Dame, 2000, 1958(1ed.).

POSSAS, M. "A cheia do mainstream: comentário sobre os rumos da ciência econômica”, Revista de Economia Contemporânea, n.1, Jan-Jun, UFRJ, Rio de Janeiro, 1997.

PRADO, B., e CASS, M.J. “A Retórica da Economia segundo McCloskey”, em Retórica na Economia, José Márcio Rego (org.), Editora 34, São Paulo, 1996.

REGO, J.M. "Retórica na Economia - idéias no lugar” em Retórica na Economia, José Márcio Rego (org.), Editora 34, São Paulo, 1996.

"Retórica no processo inflacionário: a teoria da inflação inercial”, em Inflação e Hiperinflação, Interpretações e Retórica, ed. Bienal, São Paulo, 1990.

ROSSER, B. "Complex Dynamics in New Keynesian and Post Keynesian Economics”, Post Keynesian Thought Internet Seminars, 1996.

RUTHERFORD M. Institutions in Economics, the Old and the New institutionalism, Cambridge University Press, Cambridge, 1994.

SILVEIRA, A. M. "A sedição da Escolha Pública” em Retórica na Economia, José Márcio Rego (org.), Editora 34, São Paulo, 1996.

TOYOSHIMA, S. "Instituições e Desenvolvimento Econômico - Uma Análise Crítica das Idéias de Douglass North", Ipe-Usp, Estudos Econômicos, vol. 29, n 1, 1999.

VELASCO e CRUZ, S.C. “Teoria e História: Nota Crítica sobre o Tema da Mudança Institucional em Douglass North”, texto do II Seminário Brasileiro da Nova Economia Institucional, Campinas, 2001. 